\title{
Vector Competence of Aedes caspius and Ae. albopictus Mosquitoes for Zika Virus, Spain
}

\author{
Rafael Gutiérrez-López, Sean M. Bialosuknia, \\ Alexander T. Ciota, Tomás Montalvo, \\ Josue Martínez-de la Puente, Laura Gangoso, \\ Jordi Figuerola, Laura D. Kramer
}

We assessed the vector competence of Aedes caspius and Aedes albopictus mosquitoes in Spain for the transmission of Zika virus. Whereas Ae. albopictus mosquitoes were a competent vector, Ae. caspius mosquitoes were unable to transmit Zika virus. We also identified high levels of vertical transmission of Zika virus in Ae. albopictus mosquitoes.

$\mathrm{Z}$ ika virus is an emerging arbovirus of the family Flaviviridae primarily transmitted by Aedes aegypti mosquitoes, but other Aedes species mosquitoes could be competent vectors (1). Ae. aegypti mosquitoes are absent from most countries in Europe (2), and the invasive $A e$. albopictus mosquito and other native species could create novel epidemiologic scenarios for Zika virus. Indeed, Ae. albopictus mosquito populations from Europe are competent vectors for Zika virus $(3,4)$. However, the vector competence for transmission of Zika virus of most mosquito species of Europe is currently unknown and may vary across virus strains and mosquito populations (5).

Although no autochthonous vectorborne Zika virus transmission has been reported in Spain, $\geq 316$ imported cases of Zika virus have been confirmed ( 6 ). The confirmed cases, together with the presence of both the Ae. albopictus mosquito (7) and the native Ae. caspius mosquito $(8,9)($ a potential vector of chikungunya virus [10] and Rift Valley fever virus [11]), indicate a risk for Zika virus transmission in Spain. Accurately quantifying this risk requires evaluating the competence of these mosquito species for Zika virus.

We determined vector competence at different days postinfection (dpi) by exposing F0 generation of Ae. caspius

\footnotetext{
Author affiliations: Estación Biológica de Doñana, Seville, Spain

(R. Gutiérrez-López, J. Martínez-de la Puente, L. Gangoso,

J. Figuerola); New York State Department of Health, Slingerlands, New York, USA (S.M. Bialosuknia, A.T. Ciota, L.D. Kramer); Agència de Salut Pública de Barcelona, Barcelona, Spain (T. Montalvo); Centro de Investigación Biomédica en Red de Epidemiología y Salud Pública (CIBERESP), Barcelona

(T. Montalvo, J. Martínez-de la Puente, J. Figuerola)
}

mosquitoes (collected as larvae in Huelva, Spain, because we were unable to rear it under laboratory conditions) and F2 generation of Ae. albopictus mosquitoes (collected as eggs in Barcelona, Spain) to Zika virus through infectious blood meals. We used F8 generation of colonized populations of Ae. aegypti mosquitoes (collected in Poza Rica, Mexico) as a control population and Zika virus strains CAM (2010 Cambodia; GenBank accession no. JN860885) and PR (2015 Puerto Rico; GenBank accession no. KU501215), passaged 4 times on Vero cells and 2 times on C6/36 cells. We propagated on C6/36 cells for 4 days, and freshly harvested supernatant was mixed 1:1 with sheep blood (Colorado Serum Company, http://www.thepeakofquality.com) and $2.5 \%$ sucrose (5).

We offered to 4- to 7-day-old Ae. albopictus and Ae. aegypti female mosquitoes infectious blood meals containing either the CAM or PR strain at a final concentration of $7.6 \log _{10} P F U / m L$. Infection rates were determined by screening mosquitoes' bodies, dissemination rates by screening legs, and transmission rates by screening saliva, at 3 different time points (7,14 and $21 \mathrm{dpi}$ ) using Zikaspecific quantitative reverse transcription PCR including negative controls in each reaction (12) (Table 1; Appendix, https://wwwnc.cdc.gov/EID/article/25/2/17-1123-App1. pdf). We calculated Zika titers from standard curves on the basis of infectious particle standards created from matched virus stocks (5).

We further exposed 4- to 10-day-old Ae. caspius female mosquitoes to the PR strain as described. We conducted 3 independent trials using different Zika virus concentrations at different time points $(7,14$, or $21 \mathrm{dpi})$ for each trial (Table 1; Appendix).

To determine the ability of Ae. albopictus mosquitoes to vertically transmit Zika virus, 4- to 7-day-old females were infected with Zika PR as described, and noninfectious blood meals were offered weekly after the first oviposition. We collected eggs laid in the second oviposition and hatched them for subsequent testing. We grouped second instar larvae in pools of 5 individuals and tested them for Zika virus (13). We estimated vertical transmission rate, measured as filial infection rate using the maximumlikelihood method (PoolInfRate version 4.0, https://www. cdc.gov/westnile/resourcepages/mosqSurvSoft.html) (13).

We performed generalized linear models with binomial error distribution and logit link function to assess the effect of mosquito species, virus strains, and dpi on the 
Table 1. Infection, dissemination, and transmission rates of mosquitoes experimentally infected with 2 Zika virus strains, Spain

\begin{tabular}{|c|c|c|c|c|c|c|}
\hline $\begin{array}{l}\text { Days } \\
\text { postinfection }\end{array}$ & Mosquito species & $\begin{array}{l}\text { Zika virus } \\
\text { strain* }\end{array}$ & $\begin{array}{c}\text { Blood meal titers, } \\
\log _{10} \text { PFU } / \mathrm{mL}\end{array}$ & $\begin{array}{c}\% \text { Infected (total } \\
\text { no.) }\end{array}$ & $\begin{array}{c}\% \text { Infected } \\
\text { disseminating }\end{array}$ & $\begin{array}{c}\% \text { Infected } \\
\text { transmitting }\end{array}$ \\
\hline \multirow[t]{5}{*}{7} & \multirow[t]{2}{*}{ Aedes aegypti } & CAM & 7.6 & $24.2(33)$ & 75 & 12.5 \\
\hline & & PR & 7.6 & $61.8(34)$ & 38.1 & 0 \\
\hline & \multirow[t]{2}{*}{ Ae. albopictus } & CAM & 7.6 & $90.5(21)$ & 42 & 10.5 \\
\hline & & PR & 7.6 & $97.0(33)$ & 31.3 & 0 \\
\hline & Ae. caspius & PR & 7.7 & $21.4(14)$ & 0 & 0 \\
\hline \multirow[t]{5}{*}{14} & \multirow[t]{2}{*}{ Ae. aegypti } & CAM & 7.6 & $22.6(31)$ & 71.4 & 14.3 \\
\hline & & PR & 7.6 & $45(40)$ & 77.8 & 16.7 \\
\hline & \multirow[t]{2}{*}{ Ae. albopictus } & CAM & 7.6 & $81.5(27)$ & 81.8 & 9.1 \\
\hline & & PR & 7.6 & $93.3(30)$ & 67.9 & 0 \\
\hline & Ae. caspius & PR & 8.7 & $40(25)$ & 0 & 0 \\
\hline \multirow[t]{5}{*}{21} & \multirow[t]{2}{*}{ Ae. aegypti } & CAM & 7.6 & $35.7(28)$ & 100 & 40 \\
\hline & & PR & 7.6 & $56.3(32)$ & 88.9 & 38.9 \\
\hline & \multirow[t]{2}{*}{ Ae. albopictus } & CAM & 7.6 & $94.4(18)$ & 82.4 & 23.6 \\
\hline & & PR & 7.6 & $96.2(26)$ & 96 & 36 \\
\hline & Ae. caspius & PR & 7.6 & $18.5(27)$ & 0 & 0 \\
\hline
\end{tabular}

infection, dissemination, and transmission rates. We also considered the interactions between virus strain and dpi and between virus strain and mosquito species. We determined differences in mean viral titers between mosquito species, virus strains, and dpi in mosquito body, legs, and saliva using Kruskal-Wallis tests. Analyses were run in JMP version 9 (SAS Institute, http://www.jmp.com).

Infection rate was higher in Ae. albopictus than in Ae. aegypti mosquitoes, and Zika PR had a higher infection rate than Zika CAM. Dissemination rate increased with time (dpi) but was similar between mosquito species and Zika strains. Transmission rate also increased with time, and mosquitoes infected with Zika CAM showed a higher transmission rate than those infected with Zika PR. Transmission rate did not differ between Ae. albopictus and Ae. aegypti mosquitoes (Table 1,2). Mean viral titers in bodies differed between mosquito species and Zika strains, with higher titers in Ae. albopictus compared with Ae. aegypti mosquitoes $\left(\chi^{2}=5.09, \mathrm{df}=1 ; \mathrm{p}<0.02\right)$ and higher titers for Zika PR compared with Zika CAM $\left(\chi^{2}=6.92, \mathrm{df}=1\right.$; $\mathrm{p}<0.009)$. Mean viral titers in legs were similar for both Zika strains $\left(\chi^{2}=0.95, \mathrm{df}=1 ; \mathrm{p}=0.33\right)$, but were higher in Ae. aegypti relative to Ae. albopictus mosquitoes $\left(\chi^{2}=9.53\right.$, $\mathrm{df}=1 ; \mathrm{p}<0.002)$. Mean viral titers did not differ in saliva secretions between mosquito species $\left(\chi^{2}=1.7, \mathrm{df}=1 ; \mathrm{p}\right.$ $=0.19)$ or Zika strains $\left(\chi^{2}=1.02, \mathrm{df}=1 ; \mathrm{p}=0.31\right)$. We detected Zika virus infection in Ae. caspius mosquitoes at 7,14 , and $21 \mathrm{dpi}$, but detected no virus dissemination or transmission at any point (Table 1). Five larval pools of
Ae. albopictus mosquitoes $(29.4 \% ; \mathrm{N}=17)$ were positive for Zika virus, with a filial infection rate of $72.2(95 \% \mathrm{CI}$ 27.6-156.1) and mean viral load of $2.5 \log _{10} \mathrm{PFU} / \mathrm{mL}$. This value equates to a ratio of 1:14.

Our results suggest Ae. albopictus mosquitoes in Spain are competent vectors of Zika virus at levels similar to Ae. aegypti mosquitoes. We detected Zika CAM in saliva earlier than Zika PR, which suggests that genetically variable strains may have different transmission potential (5). Although a similar transmission rate was found in $A e$. albopictus mosquitoes from Spain and Italy (3), lower rates were measured in populations in France (4). In addition, Ae. albopictus mosquitoes from Spain could transmit Zika virus at $7 \mathrm{dpi}, 4$ days earlier than mosquitoes in Italy (4). These discrepancies may be explained by variation in vector competence between mosquito populations and virus strains (5). Although Zika virus can infect Ae. caspius mosquitoes, it is unable to escape the midgut and be effectively transmitted (14).

Zika virus is vertically transmitted by the population of Ae. albopictus mosquitoes in Spain at substantially higher rates than found in Ae. albopictus mosquitoes from New York and Italy $(4,13)$ and for other flaviviruses $(15)$. These results suggest that the ability of Zika virus to be transmitted vertically is highly population dependent and could contribute to maintenance of the virus in Ae. albopictus mosquitoes in Spain.

Our results confirm that populations of Ae. albopictus mosquitoes increase the risk for Zika virus transmission in

\begin{tabular}{|c|c|c|c|c|c|c|c|c|c|}
\hline \multirow[b]{2}{*}{ Variable } & \multicolumn{3}{|c|}{ Infection rate } & \multicolumn{3}{|c|}{ Dissemination rate } & \multicolumn{3}{|c|}{ Transmission rate } \\
\hline & $\chi^{2}$ & df & $p$ value & $\chi^{2}$ & $d f$ & $p$ value & $\chi^{2}$ & df & $p$ value \\
\hline Mosquito species & 110.95 & 1 & $<0.001$ & 2.08 & 1 & 0.15 & 2.37 & 1 & 0.12 \\
\hline Zika virus strain & 10.43 & 1 & 0.001 & 1.28 & 1 & 0.26 & 4.91 & 1 & 0.03 \\
\hline dpi & 0.15 & 1 & 0.70 & 39.61 & 1 & $<0.001$ & 26.77 & 1 & $<0.001$ \\
\hline Zika virus strain $\cdot$ dpi & 1.17 & 1 & 0.28 & 1.34 & 1 & 0.25 & 6.70 & 1 & 0.01 \\
\hline Mosquito species $\cdot$ Zika virus strain & 0.01 & 1 & 0.90 & 0.76 & 1 & 0.39 & 0.01 & 1 & 0.94 \\
\hline
\end{tabular}

*Bold indicates significant effect; • indicates interaction between variables; dpi, days postinfection. 
Spain. The high number of imported Zika virus cases and the rapid spread of Ae. albopictus mosquitoes contribute to the risk for autochthonous transmission of Zika virus. The risk for transmission by Ae. caspius mosquitoes, however, may be considered extremely low.

\section{Acknowledgments}

We thank A. Díez, M. Ferraguti, A. Pastoriza, and L. Gómez for helping during fieldwork. We thank members of the New York State Department of Health Arbovirus Laboratory staff for their assistance.

Projects CGL2012-30759 (BES-2013-065274) and CGL2015-65055P from MINECO supported this study.

\section{About the Author}

Dr. Gutiérrez-López is a researcher at Estación Biológica de Doñana interested in the study of vector competence of European mosquitoes for different vectorborne pathogens.

\section{References}

1. Weger-Lucarelli J, Rückert C, Chotiwan N, Nguyen C, Garcia Luna SM, Fauver JR, et al. Vector competence of American mosquitoes for three strains of Zika virus. PLoS Negl Trop Dis. 2016;10:e0005101. http://dx.doi.org/10.1371/journal.pntd.0005101

2. European Centre for Disease Prevention and Control and European Food Safety Authority. Mosquito maps. 2018 [cited 2018 Dec 7]. https://ecdc.europa.eu/en/disease-vectors/surveillance-and-diseasedata/mosquito-maps

3. Jupille H, Seixas G, Mousson L, Sousa CA, Failloux AB. Zika virus, a new threat for Europe? PLoS Negl Trop Dis. 2016;10:e004901. http://dx.doi.org/10.1371/journal.pntd.0004901

4. Di Luca M, Severini F, Toma L, Boccolini D, Romi R, Remoli ME, et al. Experimental studies of susceptibility of Italian Aedes albopictus to Zika virus. Euro Surveill. 2016;21:30223. http://dx.doi.org/10.2807/1560-7917.ES.2016.21.18.30223

5. Ciota AT, Bialosuknia SM, Zink SD, Brecher M, Ehrbar DJ, Morrissette MN, et al. Effects of Zika virus strain and Aedes mosquito species on vector competence. Emerg Infect Dis. 2017;23:1110-7. PubMed http://dx.doi.org/10.3201/ eid2307.161633

6. Ministerio de sanidad, servicios sociales e igualdad del gobierno de España. Rapid assessment of the risk of transmission of Zika virus infection in Spain [in Spanish]. 2017 Mar 23 [cited 2018 Dec 7]. https://www.msssi.gob.es/profesionales/saludPublica/ ccayes/alertasActual/DocsZika/ERR_Zika_8-actualizacion.pdf

7. Millet JP, Montalvo T, Bueno-Marí R, Romero-Tamarit A, Prats-Uribe A, Fernández L, et al.; Zika Working Group in Barcelona. Imported Zika virus in a European city: how to prevent local transmission? Front Microbiol. 2017;8:1319. http://dx.doi.org/10.3389/fmicb.2017.01319

8. Balenghien T, Fouque F, Sabatier P, Bicout DJ. Horse-, bird-, and human-seeking behavior and seasonal abundance of mosquitoes in a West Nile virus focus of southern France. J Med Entomol. 2006;43:936-46. http://dx.doi.org/10.1093/ jmedent/43.5.936

9. Fontenille D, Failloux AB, Romi R. Should we expect chikungunya and dengue in southern Europe? In: Takken W, Knols B, editors. Emerging pests and vectorborne diseases in Europe. Wageningen (the Netherlands): Wageningen Academic Publishers; 2007. p. 169-84.

10. Vazeille M, Jeannin C, Martin E, Schaffner F, Failloux AB. Chikungunya: a risk for Mediterranean countries? Acta Trop. 2008;105:200-2. http://dx.doi.org/10.1016/j.actatropica. 2007.09.009

11. Turell MJ, Presley SM, Gad AM, Cope SE, Dohm DJ, Morrill JC, et al. Vector competence of Egyptian mosquitoes for Rift Valley fever virus. Am J Trop Med Hyg. 1996;54:136-9. http://dx.doi.org/10.4269/ajtmh.1996.54.136

12. Lanciotti RS, Kosoy OL, Laven JJ, Velez JO, Lambert AJ, Johnson AJ, et al. Genetic and serologic properties of Zika virus associated with an epidemic, Yap State, Micronesia, 2007. Emerg Infect Dis. 2008;14:1232-9. http://dx.doi.org/10.3201/ eid1408.080287

13. Ciota AT, Bialosuknia SM, Ehrbar DJ, Kramer LD. Vertical transmission of Zika virus by Aedes aegypti and Ae. albopictus mosquitoes. Emerg Infect Dis. 2017;23:880-2. http://dx.doi.org/ 10.3201/eid2305.162041

14. Hardy JL, Houk EJ, Kramer LD, Reeves WC. Intrinsic factors affecting vector competence of mosquitoes for arboviruses. Annu Rev Entomol. 1983;28:229-62. http://dx.doi.org/10.1146/annurev. en.28.010183.001305

15. Smartt CT, Stenn TMS, Chen TY, Teixeira MG, Queiroz EP, Souza Dos Santos L, et al. Evidence of Zika virus RNA fragments in Aedes albopictus (Diptera: Culicidae) field-collected eggs from Camaçari, Bahia, Brazil. J Med Entomol. 2017;54:1085-7. http://dx.doi.org/10.1093/jme/tjx058

Address for correspondence: Rafael Gutiérrez-López, Estación Biólogica de Doñana CSIC—Wetland Ecology, Av. Americo Vespucio, 26, Seville 41092, Spain; email: rgutierrez@ebd.csic.es 